We will try to publish authors' responses in the same edition with readers' comments. Time constraints might prevent this in some cases. The problem is compounded in a bimonthly journal where continuity of comment and redress are difficult to achieve. When the redress appears 2 months after the comment, 4 months will have passed since the original article was published. We would therefore suggest to our readers that their correspondence about published papers be submitted as soon as possible after the article appears.

\section{Pediatric Admissions by Family Physicians}

To the Editor: The article on pediatric admissions (Bertolino JG, Gessner TP. Pediatric admissions by family physicians and pediatricians in a semirural environment: implications for residency training. $\mathrm{J} \mathrm{Am}$ Board Fam Pract 1999;12:128-32) gave me a slight journalistic pang as it reminded me of a previous attempt to write an article comparing the actual admitting practices of pediatricians with those of family physicians. I have many times regretted that I did not do the study, but here is the anecdotal setting:

When I first went into rural practice more than 30 years ago (St Mary's County, Md), the only general physicians in the county were general practitioners. These physicians did everything except operating room surgery. All of us had extensive obstetric practices and, of course, pediatric practices.

Eventually specialization came to the county, and pediatricians began taking care of newborns as well as children in this rural community. At that time many of us thought there was a great opportunity to do a study comparing the admitting practices of pediatricians and family physicians.

It was common for nurses at our rural community hospital to say to one of us, "What are all these kids doing in here?" Obviously family physicians were admitting far less frequently than pediatricians, in many cases for the same clinical problems. This pattern very clearly illustrated to the medical staff and to the nursing staff the differences in training and approach to childhood illness between the two types of physicians. A member of the general practice group would often lament that we did not seem to have time enough to do the study, but it would be a fascinating one.

And so, the great opportunity was lost and is now only a clinical memory, but it is still a source of amusement when the old-timers get together and reminisce.

Eugene Guazzo, MD

Chaptico, $\mathrm{Md}$

\section{Family Physcians as Generalists}

To the Editor: My compliments to Dr. Halvorsen (Halvorsen J. Who am I, professionally speaking? JABFP $1999 ; 12: 173-7)$. He has articulated well the dilemma that we family physicians have faced since our name changed from general practitioner to family physician. I was part of that transition and had strong feelings about keeping the general physician designation. Obviously, other ideals prevailed, and since I did not then and do not now believe that family physician is a specialty similar to other specialties, our name and designations need reflect something different.

Other specialties, which have had a reductionistic character, have not achieved generalist status before becoming an "added special value" specialty. It has been distracting to watch the language elevate the more generic term specialist while denigrating the term generalist.

Family physicians have not been able to convince themselves or others that the terms and their implied defining characteristics have promoted the equality we believe we deserved.

I have always promoted the concept that family physicians are indeed generalists in the broad sense. In my quest for equality, I have advocated equally fervently that the other reductionistic specialties should be lumped under the broad term narrowist. I have long believed that such designations would have gone far in the descriptions of roles and domains of generalist family physicians and their narrowist counterparts.

I hope my younger and more avid counterparts will carry on this nomenclatural crusade and help put family physicians in the niche of the medical hierarchy we have so long sought.

H. E. "Pat" Crow, MD Sun City Center, Fla 